\title{
Pembuatan gigitiruan jembatan anterior pada lingir alveolar yang resorpsi Making anterior denture bridge on resorpted alveolar ridge
}

\author{
Aprillia Adenan, Taufik Sumarsongko \\ Bagian Prostodonsia \\ Fakultas Kedokteran Gigi, Universitas Padjadjaran \\ Bandung, Indonesia
}

\begin{abstract}
Bridge is a partial denture that attached permanently to the abutment, to replace missing natural teeth. It is easy to make GTJ on normal elveolar ridge. But if the alveolar have already resorpted, pontik form need to be modified to make artificial gingiva to look aesthetic. This paper reported the case of a 40-year-old man that has lost tooth 21 and 22 for eight years. For two last years ago he used a removable denture. Patients feel uncomfort and less satisfied, so he wanted to made a new denture, a fixed denture and more comfortable. After intra oral and radiographic examination, conventional metal ceramics made on 11,21,22, 23 with the abutments at 11 and 23, as well as pontik 21 and 22 and the addition of artificial gingiva in the area resorption. The bridge was seen aesthetic. Key words: denture conventional bridges, pontik, artificial gingiva, alveolar resorption
\end{abstract}

\begin{abstract}
ABSTRAK
Gigitiruan jembatan (GTJ) adalah gigitiruan sebagian yang dilekatkan secara permanen pada gigi penyangga untuk menggantikan gigi alami yang hilang. Jika GTJ dibuat pada lingir yang normal, tidak ada menimbulkan masalah. Akan tetapi bila lingir sudah mengalami resorpsi, bentuk akhiran pontik perlu dimodifikasi dengan membuat gingiva buatan agar terlihat estetik. Pada makalah ini dilaporkan kasus seorang pria berumur 40 tahun telah kehilangan gigi 21 dan 22 selama delapan tahun, tetapi dua tahun yang lalu telah dibuatkan gigitiruan lepasan. Pasien merasa tidak nyaman dan kurang puas, sehingga ingin dibuatkan gigi tiruan baru yang tidak bisa dilepas, dan nyaman dipakai. Setelah dilakukan pemeriksaan di dalam mulut dan pemeriksaan radiografi, kemudian dibuatkan GTJ konvensional metal keramik 11, 21, 22, 23 dengan gigi penyangga pada 11 dan 23, serta pontik 21 dan 22 serta penambahan gingiva buatan di daerah lingir yang resorpsi pada pontik sehingga GTJ terlihat estetik.
\end{abstract}

Kata kunci: gigitiruan jembatan konvensional, pontik, gingiva buatan, lingir resorpsi

Koresponden: Aprillia Adenan, Bagian Prostodonsia, Fakultas Kedokteran Gigi, Universitas Padjadjaran, Bandung, Indonesia. E-mail: prostounpad@yahoo.com

\section{PENDAHULUAN}

Gigitiruan jembatan (GTJ) yang lazim disebut fixed partial denture adalah gigitiruan sebagian yang dilekatkan secara tetap pada satu atau lebih gigi penyangga dan tidak dapat dilepas oleh pemakainya. Apabila seseorang kehilangan satu atau beberapa gigi, terutama gigi anterior, akan mengganggu tampilan dan saat bicara sehingga penderita merasa tidak percaya diri, sebaliknya jika kehilangan gigi posterior akan mengganggu fungsi pengunyahan., ${ }^{1,2}$ Pada kasus ini penderita telah kehilangan gigi 21 dan 22 selama 8 tahun, lingir alveolar sudah mengalami resorpsi, sehingga kalau dibuatkan GTJ perlu memperbaiki bentuk akhiran pontik supaya terlihat estetis. Sejak 2 tahun yang lalu pasien sudah memakai gigitiruan lepasan menggantikan 2 gigi anterior tetapi kurang nyaman dan tidak puas, serta ingin menggantikannya dengan gigitiruan baru yang tidak bisa dilepas, untuk memperbaiki penampilan. Ada macammacam GTJ, yaitu GTJ fixed-fixed, GTJ semi fixed, GTJ kantilever, GTJ spring cantilever; semuanya digolongkan GTJ konvensional karena desain retensinya tidak tergantung pada teknik adesif. ${ }^{1}$ Ada juga GTJ adesif yang perlekatan dengan gigi penyangga menggunakan semen adesif dan teknik etsa asam.

Untuk pembuatan GTJ diperlukan beberapa pertimbangan yang disesuaikan dengan kasus, rencana perawatan, preparasi gigi dan bahan restorasi. Penggantian gigi pada daerah anterior rahang atas merupakan suatu tantangan karena faktor kesulitan yang tinggi untuk penatalaksanaan jaringan lunak dan disain pontiknya. Tujuan dari pembuatan gigitiruan adalah memulihkan daya kunyah, memperbaiki estetik, mencegah migrasirotasi-ektrusi, memperbaiki pengucapan, menjaga kesehatan jaringan lunak serta mencegah terjadinya kerusakan lebih lanjut dari struktur organ di dalam rongga mulut. ${ }^{2}$ Untuk mencapai tujuan tersebut maka kondisi struktur jaringan pendukung gigi perlu diperhatikan. Pada keadaan lingir yang belum mengalami resorpsi, pembuatan GTJ belumlah merupakan masalah. Akan tetapi jika telah terjadi resorpsi diperlukan penanganan khusus. Pembuatan gigitiruan untuk menggantikan gigi alami yang 
hilang dapat dibuat secara lepasan, ataupun cekat, tergantung kondisi penderitanya. Tulang alveolar merupakan bagian tulang kraniomaksilofasial yang memberikan dukungan pada gigi. Lingir alveolar yang merupakan salah satu pendukung gigitiruan sering kali merupakan faktor pertimbangan dalam menentukan rencana perawatan. ${ }^{3}$ Resorpsi tulang alveolar terjadi setelah pencabutan gigi terutama pada tahun pertama. Tingkat kecepatan resorpsi lingir alveolar berbeda antara rahang atas dengan rahang bawah, dengan perbandingan rata-rata 1:4. Kecepatan resorpsi rahang bawah lebih besar daripada rahang atas. ${ }^{3}$ Resorpsi pada lingir alveolar bagian anterior rahang atas cenderung ke arah belakang dan ke atas dengan tingkat kehilangan tulang yang cukup progresif. Pada bagian posterior rahang atas resorpsi cenderung ke arah atas dan ke dalam sehingga lingir alveolar mengecil secara progresif. Kalau lingir alveolar rahang bawah anterior dan posterior mengalami resorpsi ke arah depan dan bawah. ${ }^{3}$ Tingginya tingkat resorpsi lingir alveolar setelah pencabutan gigi akan menentukan apakah dibuat gigitiruan lepasan atau gigitiruan cekat.

Seperti diketahui pontik adalah bagian dari GTJ yang menggantikan gigi alami yang telah dicabut, memperbaiki fungsi dan penampilan. Pontik harus dibuat sesuai dengan keberhasilan pemeliharaan kesehatan dan kenyamanan rongga mulut. ${ }^{1,4,5}$ Sebelum gigitiruan cekat dibuat pada daerah tidak bergigi, harus diperhatikan dalam merencanakan perawatan. Resorpsi tulang dapat terjadi secara vertikal dan horisontal. Pada resorpsi vertikal terjadi dimensi apikokoronal yang lebih pendek dibandingkan dengan gigi di sebelahnya. Sedangkan pada resorpsi horisontal menyebabkan kecekungan pada dimensi bukolingual. ${ }^{6}$ Kedua tipe resorsi ini mengakibatkan keadaan yang kurang estetis. Bentuk tulang dan topografi daerah harus dievaluasi, tipe dan banyaknya destruksi tulang berperan dalam pemilihan pontik. ${ }^{4}$
Siebert mengklasifikasi deformasi bentuk tulang alveolar tersisa ada tiga kelompok, yaitu Klas I kehilangan lebar fasiolingual dengan tinggi apikokoronal normal, Klas II kehilangan tinggi lingir dengan lebar normal, dan Klas III kehilangan keduanya tinggi dan lebar lingir. ${ }^{4,5}$ Pasien ini pasien termasuk katagori kerusakan kelas III, sehingga perlu memodifikasi bentuk akhiran pontik. Pontik harus dapat menyesuaikan dengan kesehatan mulut dan kenyamanan pasien ${ }^{1,4,5}$

Pada artikel ini akan dilaporkan mengenai penanganan penderita kehilangan dua gigi anterior yang disertai resorpsi lingir alveolar dengan cara pembuatan gigitiruan jembatan konvensional disertai modifikasi gingiva buatan.

\section{KASUS}

Seorang laki-laki berumur 40 tahun karyawan swasta datang ke Klinik Spesialis Prostodonsia Rumah Sakit Gigi dan Mulut Fakultas Kedokteran Gigi Universitas Padjajaran dengan keluhan ingin dibuatkan gigitiruan yang tidak bisa dilepas, karena sudah memakai gigitiruan lepasan dan merasa tidak nyaman. Setelah dilakukan pemeriksaan di dalam mulut diketahui pasien kehilangan gigi 21 dan 22 (Gambar 1) kemudian dilakukan pemeriksaan radiografi. Terlihat lingir pada daerah tidak bergigi sudah menipis dan terjadi resorpsi pada lingir.

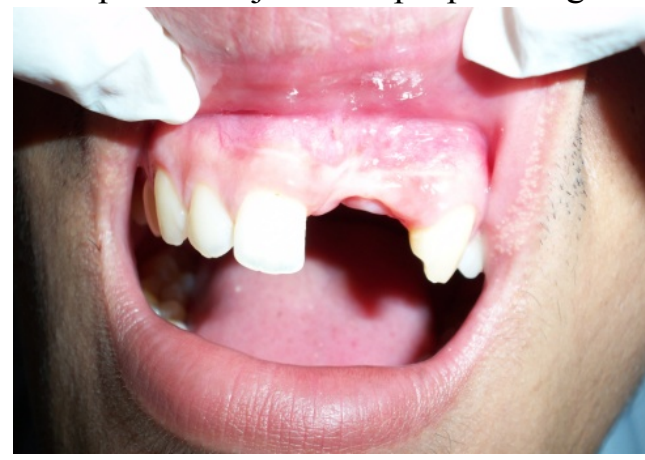

Gambar 1 Gambaran klinis pasien sebelum perawatan kehilangan gigi 21 dan 22 dengan resorpsi pada lingirnya.
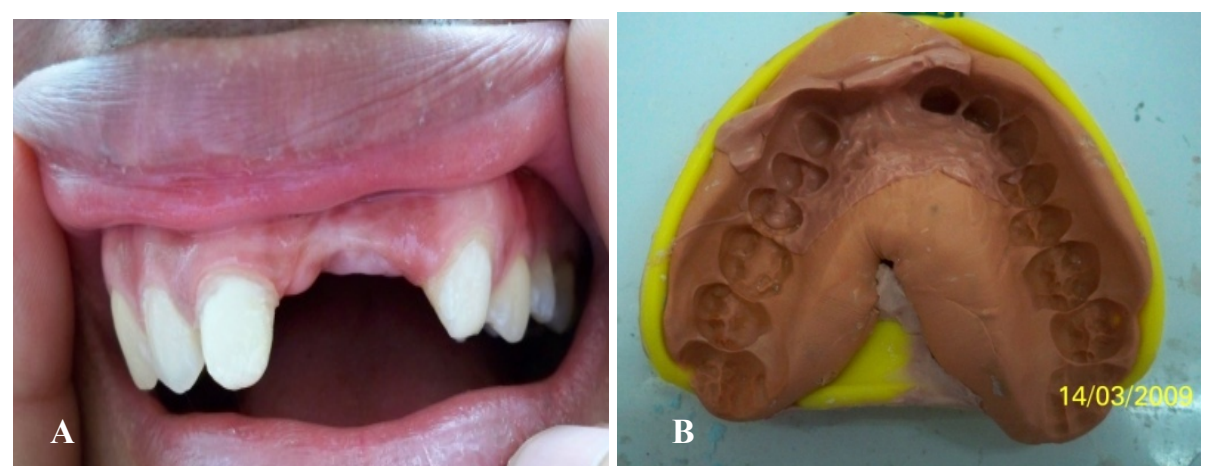

Gambar 2A Gigi penyangga 11 dan 23 sudah dipreparasi, B cetakan hasil preparasi dengan bahan elastomer. 

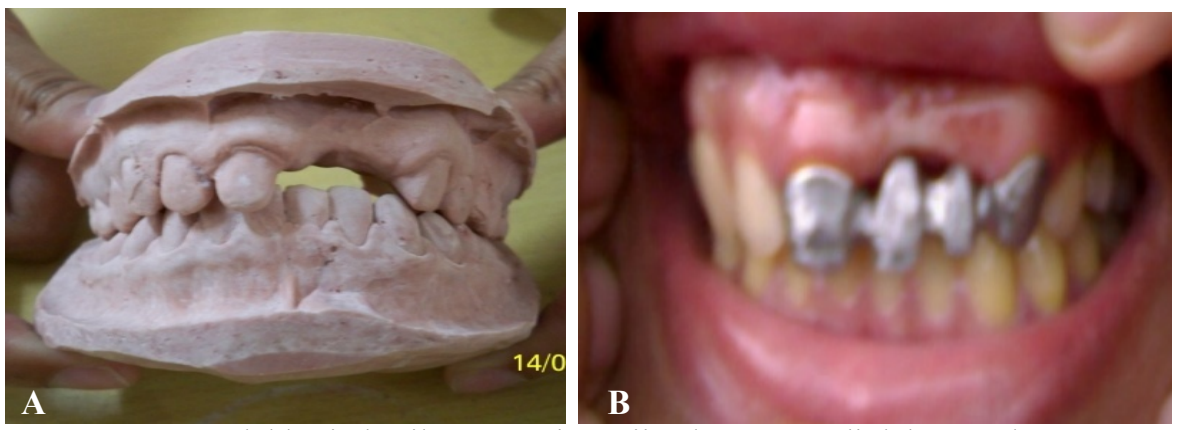

Gambar 3A Model kerja hasil preparasi, B uji coba coping di dalam mulut.

Terdapat beberapa alternatif perawatan yang direncanakan, yaitu pembuatan gigitiruan lepasan,GTJ adesif, GTJ konvensional akrilik atau metal keramik 11, 21, 22, 23 dengan penambahan gingiva buatan di servikal pontik, melakukan pembedahan lingir sebelum pemasangan GTJ, dan pemasangan implan gigi 21 dan 22. Setelah diskusi dan 22. Setelah diskusi mengenai kelebihan dan kekurangan perawatan, pasien memilih GTJ konvensional metal keramik dan penambahan gingiva buatan pada pontik.

\section{PENATALAKSANAAN}

Pertama-tama dilakukan pencetakan rahang atas dan bawah untuk pembuatan model studi, disusul dengan pembuatan rencana perawatan pada model studi. Selanjutnya gigi penyangga 11 dan 23 dipreparasi (gambar 2A), kesejajaran kedua gigi penyangga diperiksa dengan memeriksa model gips yang diperoleh dari pencetakan yang menggunakan bahan cetak alginat. Setelah preparasi kedua gigi penyangga sedikit disempurnakan dan telah sejajar, kemudian dicetak dengan bahan cetak elastomer (gambar 2B) untuk mendapatkan model kerja (Gambar 3). Model kerja dipasang pada artikulator.

Selanjutnya dilakukan pembuatan coping GTJ pada gigi 11,21, 22, dan 23; dilanjutkan dengan uji coba coping pada pasien (Gambar 3B), lalu uji coba coping GTJ yang telah dilapis porselen. Setelah rangka logam GTJ konvensional sesuai, dilakukan penambahan porselen warna gingiva pada pontik 21 dan 22, serta GTJ porselen yang sudah lengkap diujicobakan (Gambar 4). Gigitiruan yang sudah sesuai, dilakukan glazing (Gambar 5, dan 6A).

Uji coba pemasangan GTJ dilakukan dengan penyemenan sementara. Setelah pemeriksaan klinis menyeluruh, tidak ada keluhan penderita, dilakukan penyemenan tetap GTJ 11, 21, 22, 23 (Gambar 6B). Satu minggu kemudian dilakukan penyesuaian dan kontrol (Gambar 7).

\section{PEMBAHASAN}

Terdapat beberapa metode untuk mengatasi masalah lingir alveolar yang mengalami resorpsi dalam pembuatan gigitiruan cekat. Pada keadaan lingir normal, pembuatan GTJ tidak ada kesulitan. Akan tetapi, apabila kehilangan gigi sudah lama maka lingir alveolar sudah terjadi resorpsi sehingga perlu penanganan khusus. Bentuk tulang dan topografi daerah tidak bergigi harus dievaluasi dengan hati-hati selama tahap rencana perawatan. ${ }^{4,5}$ Tinggi dan lebar lingir memungkinkan penempatan pontik yang sesuai dengan gigi tetangganya. Kehilangan bentuk lingir sisa dapat menyebabkan embrasure gingiva terbuka dan tidak estetik, terjadi impaksi makanan dan saliva keluar dari dalam mulut saat bicara. ${ }^{5}$

Siebert mengklasifikasikan penurunan bentuk tulang yang tersisa menjadi 3 katagori dan telah diterima secara umum. Terdapat insidensi yang tertinggi $(91 \%)$ dari perubahan lingir yang tersisa mengikuti hilangnya gigi anterior, terutama pada kerusakan Klas III. Pada kerusakan Klas III, sudah terjadi resorpsi lingir secara vertikal dan horisontal sehingga dimensi apikokoronal lebih pendek dan terjadi cekungan pada dimensi bukolingual. ${ }^{6}$ Pada kerusakan Klas I jarang dan tidak mengganggu estetik. Akan tetapi pada kerusakan Klas II dan III seringkali menimbulkan ketidakpuasan mengenai estetik gigitiruan sebagian cekat, sehingga operasi preprostetik yang bertujuan untuk memperbesar lingir harus dipertimbangkan dengan seksama. ${ }^{5}$ Walaupun lebar lingir sisa dapat ditambah dengan

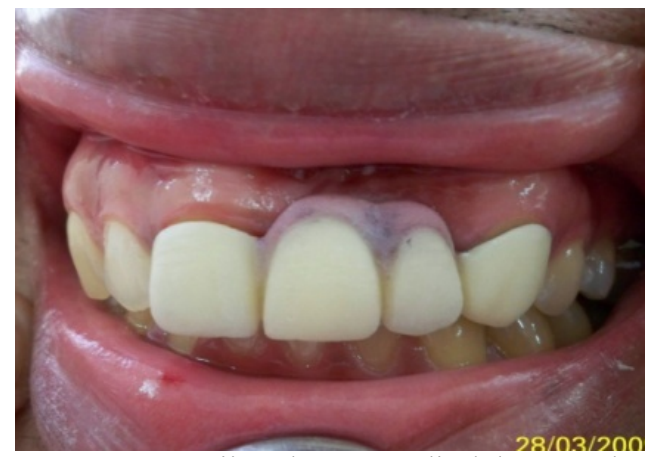

Gambar 4 Uji coba GTJ di dalam mulut sebelum di-glaze. 


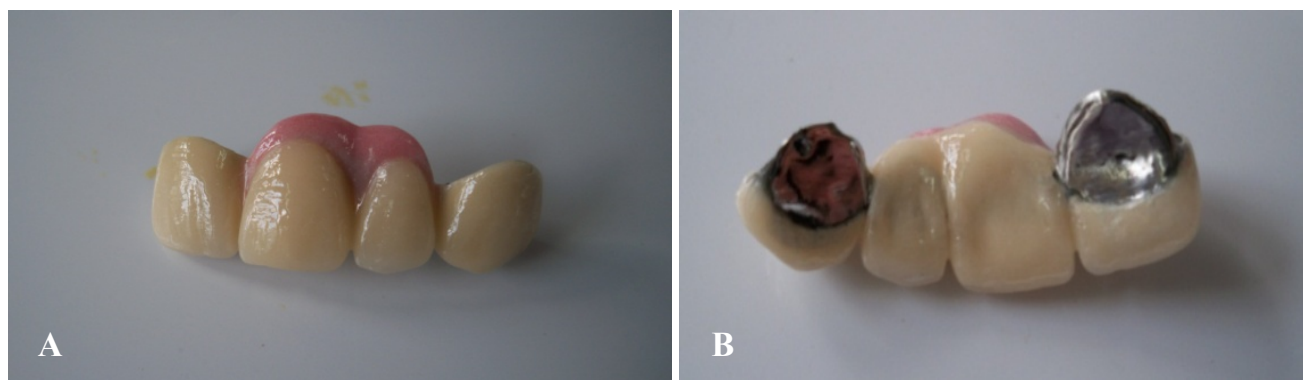

Gambar 5A Aspek labial GTJ dengan gingiva buatan telah di-glaze, B tampak dari palatal
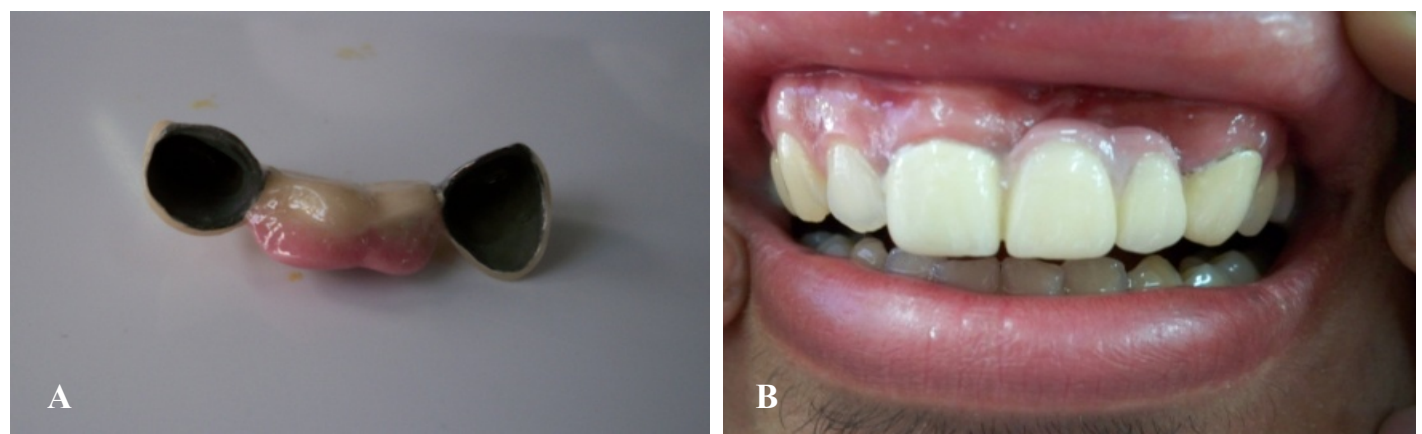

Gambar 6A Aspek apikal GTJ, B aspek labial GTJ yang telah disementasi.

graft jaringan keras, hal ini tidak diindikasikan kecuali daerah ini digunakan untuk penempatan implan. 5,7

Pada laporan kasus ini pasien kehilangan gigi 21 dan 22, serta sudah terjadi resorpsi lingir alveolar kategori Klas III, yaitu sudah terjadi resorpsi secara vertikal dan horisontal (gambar 1) lebar dan tinggi tulang sudah berkurang. Setelah didiskusikan pasien memilih pembuatan GTJ 4 unit, yaitu penyangga gigi 11 dan 23 , serta pontik 21 dan 22, dan penambahan gingiva buatan pada akhiran pontik. Pasien menolak untuk dilakukan prosedur bedah untuk memperbaiki bentuk lingir. Sebelumnya diberikan beberapa alternatif untuk mengatasi lingir alveolar yang sudah tipis/runcing dan pendek dengan pembuatan pola wax pontik dahulu pada model studi dengan bentuk gigi sesuai dengan ruang yang ada, dan bentuk gigi dengan penambahan warna gingival pada akhiran pontik. Pada kasus ini walaupun kehilangan gigi sudah 8 tahun, ruang lebar mesiodistal daerah tidak bergigi masih normal, hanya ukuran insisogingival lebih panjang karena sudah terjadi resorpsi lingir alveolar jadi perlu memodifikasi pontik. Adanya resorpsi lingir alveolar akan membuat pontik terlihat terlalu panjang di bagian servikal. Tinggi gigi terlihat jelas ketika pasien tersenyum serta memperlihatkan tepi gingiva. ${ }^{4,5}$ Pada daerah gigi hilang yang disertai resorpsi yang luas, apabila dibuat pontik dengan tinggi yang normal, pontik tidak akan seluruhnya menyentuh lingir alveolar. Pontik menjadi sangat panjang karena hilangnya dukungan vertikal tulang, solusinya adalah menirukan permukaan akar dan diberikan campuran warna oranye-coklat dengan cara membentuk cementoenamel junction (CEJ). ${ }^{1.5,8}$ Kerugiannya ialah terlihat embrasure gingiva yang terbuka yang diketahui sebagai black triangle, yang akan mengurangi estetik. ${ }^{4,5} 8$. Alternatif lain ukuran pontik dibuat normal, tetapi hanya pada akhiran pontik untuk menutupi ruang kosong dibuatkan porselin warna pink menirukan jaringan gingiva, walaupun terjadi sedikit perbedaan dengan gingiva alami pasien. ${ }^{5}$ Hasilnya, pasien cukup puas dengan pembuatan GTJ metal keramik yang dikombinasi dengan penambahan porselen warna pink pada akhiran servikal pontik.

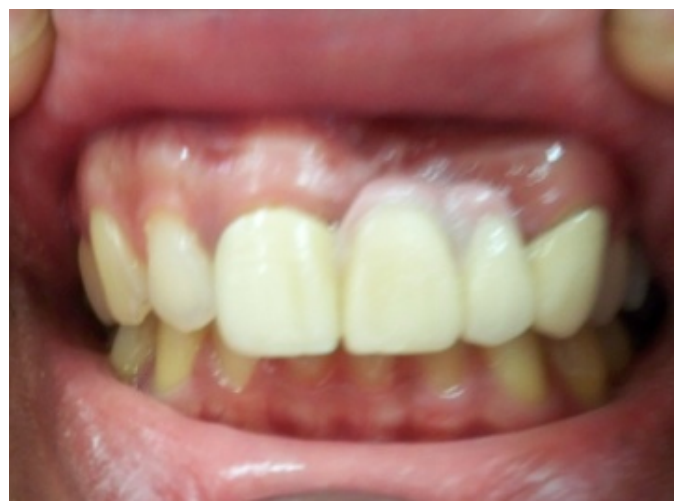

Gambar 11 Penyesuaian GTJ.

Dari pembahasan mengenai pembuatan GTJ untuk perawatan edentulus dengan lingir alveolar yang resorpsi,disimpulkan bahwa terdapat beberapa cara untuk mengatasi masalah pembuatan jembatan pada lingir alveolar yang mengalami resorpsi, salah 
satunya adalah dengan pembuatan GTJ dengan pontik sesuai dengan panjang daerah yang resorpsi dengan pewarnaan, pada daerah akar akan terlihat embrasure gingiva terbuka. Untuk mengatasi kendala estetik tersebut dilakukan pembuatan GTJ dengan penambahan gingiva buatan pada akhiran pontik dengan porselen sehingga warna gingiva terlihat lebih estetik.

\section{DAFTAR PUSTAKA}

1. Howe LC, Kontorowicsz GF. Shortall ACC. Inlay, crowns \& bridges. $5^{\text {th }}$ Ed. Oxford: Wright; 1993. p.138, 1546.

2. Martanto P. Ilmu mahkota dan jembatan. Bandung: Penerbit Alumni; 1985. hlm. 3, 228.

3. Winkler S. Clinical implant site development and alveolar bone resorpsion. J Oral Implantol 2002; 28(5): 226-9.

4. Shillingburg HT, Hobo S, Whitsett LD, Jacobi R, Brackett SE. Fundamental of fixed prosthodontics. $3^{\text {rd }}$ Ed. Chicago: Qunitessence Pub.; 1997. p.491-4.

5. Rosenstiel SF, Land MF, Fujimoto J. Contempory fixed prosthodontics, $3^{\text {rd }}$ Ed. St. Louis: Mosby; 2001; p.51339.

6. Garber DA. The Edentulous ridge in fixed prrosthodontic. $3^{\text {rd }}$ Ed. Philadelphia: Pennsylvania; 1999.

7. Capri D, Albehbehani Y, Smukler H. Augmenttion an anterior edentulous ridge for fixed prosthodontics combined use orthodontics and surgery: clinical report. J Prosthet Dent 2003; 90:115-5.

8. Nallaswamy D. Textbook of prosthodontics. Kuala Lumpur: Jaypee. p.515-6. 